\title{
POLÍTICA DIGITAL: AS MÍDIAS DIGITAIS COMO PALANQUE NA ELEIÇÃO MUNICIPAL DE BLUMENAU (SC)
}

\author{
Digital politics: digital media as a platform in the municipal election of \\ Blumenau (SC)
Política digital: los medios digitales como una plataforma en la elección municipal de Blumenau (SC)

\begin{abstract}
Moisés Cardoso
Doutorando no Programa de Pós-Graduação em Comunicação e Linguagens

Universidade Tuiuti Do Paraná beiocardoso@gmail.com

Tarcis Prado Junior

Doutorando no Programa de Pós-Graduação em Comunicação e Linguagens

Universidade Tuiuti Do Paraná tarcisjr@yahoo.com.br

Franco Iacomini Junior Doutorando no Programa de Pós-Graduação em Comunicação e Linguagens

Universidade Tuiuti Do Paraná fiacomini@gmail.com

Thaíse Schmitz Pós-graduanda em Marketing e Comunicação Digital

Dom Bosco

schthaise@gmail.com
\end{abstract}

\section{Resumo}

As campanhas eleitorais no Brasil passaram por uma reforma eleitoral, determinado pelo TSE com a Lei 13.165, que afetaram o planejamento e a abordagem comunicacional dos partidos políticos. Este artigo propõe analisar o fluxo de conteúdo e as interações comunicacionais desencadeadas na rede social digital Facebook, durante as eleições de 2016 na cidade de Blumenau/SC. Para o cumprimento do objetivo proposto, utilizaram-se as teorias de Caseiro e Barbosa (2011); De Vries, Gensler e Leeflang (2012). As abordagens foram baseadas na coleta de dados de caráter qualitativo por meio da base quantitativa, realizada nas fan pages dos candidatos e na observação do ambiente digital bem como das estratégias. Os resultados apontaram que a mudança no cenário político tradicional impulsionou os candidatos a desenvolverem novos processos comunicacionais nas plataformas digitais.

Palavras-chave: Mídias digitais. Comunicação. Política. 


\begin{abstract}
The electoral campaigns in Brazil underwent an electoral reform, determined by the TSE with Law 13.165, which affected the planning and the communicational approach of the political parties. This article proposes to analyze the flow of content and the communicational interactions triggered in the digital social network Facebook, during the 2016 elections in the city of Blumenau / SC. For the accomplishment of the proposed objective, the theories of Caseiro and Barbosa (2011) were used; De Vries, Gensler and Leeflang (2012). The approaches were based on the qualitative data collection through the quantitative base, realized in the fan pages of the candidates and in the observation of the digital environment as well as of the strategies. The results pointed out that the change in the traditional political landscape has driven the candidates to develop new communication processes in digital platforms.
\end{abstract}

Key words: Digital media. Communication. Policy.

\title{
Resumen
}

Las campañas electorales en Brasil pasaron por una reforma electoral, determinado por el TSE con la Ley 13.165, que afectó a la planificación y el enfoque comunicacional de los partidos políticos. Este artículo tiene como objetivo analizar el flujo de contenido y las interacciones comunicativas desencadenados en la red social Facebook digitales durante las elecciones de 2016 en la ciudad de Blumenau / SC. Para el cumplimiento del objetivo propuesto, hemos utilizado las teorías de la domesticada y Barbosa (2011); De Vries, Gensler y Leeflang (2012). Los enfoques se basan en la recopilación de datos cualitativos a través del estudio cuantitativo se llevó a cabo en las páginas de fans de los candidatos y de la observación del entorno digital, así como estrategias. Los resultados mostraron que el cambio en el paisaje político tradicional propulsado candidatos para desarrollar nuevos procesos de comunicación en plataformas digitales.

Palabras clave: Medios digitales. Comunicación. Política.

\section{INTRODUÇÃO}

A campanha eleitoral para câmaras municipais e prefeituras, em 2016, marcou uma ruptura nas clássicas ações de planejamento e estratégias de marketing. As modificações foram introduzidas pela Lei 13.165, acatada pelo Congresso Nacional em 29 de setembro de 2015. Chamada de "Reforma Eleitoral", ela alterou de uma única vez as leis que regem as Eleições (9.504/1997) e os Partidos Políticos (9.096/1995), bom como o Código Eleitoral (4.737/1965). A reforma teve como mote principal a diminuição dos gastos nas campanhas eleitorais, a simplificação da administração das corporações partidárias e o incentivo à participação da mulher na política (BRASIL, 2015). 
Assim, o pleito de 2016 acabou por tornar-se uma forma de incubação para o processo eleitoral de 2018 - mais amplo, incluindo a renovação dos Legislativos estaduais e da Câmara Federal, a eleição de dois terços do Senado e a escolha de governadores e presidente. Após o processo de 2016, seria possível identificar possíveis evoluções ou retrocessos, advindos das novas normativas. A partir daí, os legisladores poderiam ponderar e recomendar novas diretrizes para as leis eleitorais.

Santa Catarina foi o Estado que teve o terceiro menor índice de abstenções na eleição de 2016, com 13,01\% (PEREIRA, 2016). Entre os municípios catarinenses, a menor abstenção (1,55\%) foi em Presidente Castello Branco, no Oeste - lá, apenas 25 dos 1.611 eleitores não foram às urnas. A maior ausência foi registrada em Balneário Camboriú $(22,68 \%)$, onde 20.736 dos 91.438 eleitores faltaram à votação.

Neste contexto, destacamos que o cenário eleitoral das campanhas municipais de 2016 limitou a dinâmica de arrecadação de fundos e criminalizou o marketing político e a propaganda tradicional. O horário eleitoral desempenha um papel estratégico para a apresentação dos candidatos ao seu eleitorado. A desigualdade de tempo de exibição no rádio e na televisão para os dois concorrentes analisados nessa investigação dificultou as condições de captação de votos diante de candidatos com mais visibilidade. Em consequência, ficou dificultada a comparação entre as plataformas de governo, na visão do público.

Com um tempo reduzido na propaganda eleitoral gratuita reduzida em consequência dos arranjos das coligações e das novas resoluções eleitorais, os candidatos de menor expressão política foram forçados a usarem as redes sociais como espaço para apresentarem suas ideias e abrirem o diálogo com seus eleitores. Ou seja, o contexto de ecoar uma mensagem e do fazer político, teve sua estrutura alterada, tanto para os candidatos muita expressão como os de pequena. As campanhas eleitorais, em especialmente a de 2016, sucederam na e para a web; inclusive incluindo processos criminosos como o de fake news.

Nessa perspectiva, o objetivo do presente estudo é analisar o fluxo de conteúdo e as interações comunicacionais desencadeadas na rede social digital Facebook durante as eleições de 2016 na cidade de Blumenau (SC), a fim de entender suas estratégias de marketing digital. Para tanto, foi aplicada uma metodologia qualitativa de dados quantitativos obtidos das fan pages investigadas.

Ao analisar os estudos realizados a respeito do uso do marketing digital em campanhas políticas, é possível identificar mais de setenta e oito artigos científicos revisados por pares em revistas indexadas no Portal de Periódicos da Capes, o que consolida a importância da 
temática. Destacam-se os trabalhos de Farrell e Webb (2000); Farrell, Kolodny e Medvic (2001); Gomes et al. (2009); Howard (2005); Leppäniemi et al. (2010); Sanz (2010); entre outros. Estruturou-se o artigo nas seções: Marco Teórico, Metodologia, Apresentação e Discussão dos Resultados e Considerações Finais.

\section{DESENVOLVIMENTO}

\subsection{Marketing Digital}

A era digital evolui constantemente e essas alterações geram constantes impactos na sociedade e na vida das pessoas, acelerando as transformações no mercado, que se torna mais dinâmico e competitivo (CHIAVENATO, 2011). A crescente adesão às mídias digitais contribuiu para o desenvolvimento do marketing digital nas organizações, uma tendência e necessidade atual. A evolução da comunicação na internet fez com que o marketing tradicional evoluísse para formas em que as ações são efetivadas por meio de canais eletrônicos, de maneira que o usuário controla a quantidade e o tipo da informação que deseja receber (OLIVEIRA, 2000).

O maior impacto da web foi ter mudado o comportamento dos consumidores. No século XXI o cenário passou por uma revolução. Adaptar-se aos desafios do marketing digital requer das organizações a adoção de novas estratégias. Se as empresas não iniciarem o construto neste momento, considerando que a cada novo negócio ou oportunidade as implicações devem ser repensadas para a internet, as estratégias e objetivos possivelmente não serão alcançados (FRASER e MCDONALD, 2006).

O marketing digital intensifica a forma de fazer negócios e de aperfeiçoar o relacionamento com o consumidor. Através da internet a organização - seja ela uma empresa comercial e de serviços ou mesmo uma personalidade pública - se expõe 24 horas por dia aos seus clientes, os quais podem buscar informações e fazer comparações sem a necessidade de uma estrutura física (MORAES, 2006).

O consumidor digital tornou-se mais ativo nessa esfera global e tecnológica, não se restringindo aos meios de comunicação tradicionais, deixando de ser um mero receptor. Passou a ser transmissor e gerador de conteúdo (TELLES, 2010). Inserido em um imenso banco de dados interligado, ele passa de "passivo para ativo", possuindo maior acesso às informações, e por isso consegue conhecer, questionar, comparar e divulgar a sua opinião. 
Para realizar ações com marketing na web é necessário redirecionar a visão de mercado para obter competitividade e sucesso. As marcas devem oferecer experiências online superiores às expectativas de seus clientes, através, principalmente, de conteúdos relevantes e interações em tempo real (MORAES 2006). Vale lembrar que as premissas básicas marketing continuam valendo, no entanto, elas precisam ser adaptadas aos novos paradigmas, em que o mercado mune as necessidades e a partir delas são elaboradas as soluções (KOTLER, KARTAJAYA e SETIWAN, 2017).

Os desafios que as empresas enfrentam são diversos, e por isso há uma necessidade de satisfazer os consumidores que estão dia a dia mais exigentes. A tecnologia promoveu a proximidade com o cliente e desta maneira foi possível conhecê-lo melhor, oferecer-lhe serviços ou produtos personalizados, de acordo com suas necessidades adaptadas à natureza mutável dos consumidores na era digital (KOTLER, KARTAJAYA e SETIWAN, 2017). Para suprir as expectativas deste consumidor, é essencial desenvolver estratégias adequadas.

Neste sentido, a interatividade e a experiência são os principais aspectos para o sucesso de estratégias de marketing. Os consumidores estão se voltando para vários tipos de mídia social para buscarem maiores informações, realizarem buscas e também tomarem decisões. O consumidor digital é ativo e dinâmico, não pode ser atingido facilmente, e também é gerador de mídia. Quando se conhecem os gostos e comportamento das pessoas, maior a probabilidade de saber o que elas querem, e o que não querem (GABRIEL, 2010).

O marketing digital, além de permitir a comunicação de pessoa para pessoa, possui a vantagem de tornar possível a comunicação de um indivíduo para muitos e de muitos para milhares. Em vez de construir campanhas separadas da estratégia online, o ambiente digital permite criar plataformas continuas de interação, que engajam o público e não apenas o atingem (GABRIEL, 2010). O diálogo entre marcas e consumidores não é apenas frequente, mas bem-vinda, basta saber distinguir o que cada rede social oferece e seus recursos / abrangência na web.

\subsection{As novas regras das eleições 2016}

Nessa seção abordaremos as principais mudanças que o TSE estabeleceu nesta edição das campanhas eleitorais. Focaremos nossa atenção naquelas referentes ao financiamento da campanha e a propaganda partidária, temas diretamente relacionados ao tema desta pesquisa. Esses dois pontos estão no estágio inicial de diferentes desdobramentos comunicacionais nas 
diversas esferas envolvidas com o processo eleitoral, e isso justifica sua relevância na abordagem deste artigo.

A partir de 2016, as pessoas jurídicas estão vedadas de realizar doações para as campanhas eleitorais. Somente pessoas físicas estão habilitadas a doar valores em dinheiro para campanhas, e mesmo assim com um limite de $10 \%$ dos rendimentos brutos do doador do ano precedente à eleição. Essa mudança influencia diretamente o planejamento e as estratégias comunicacionais da política. Até então, a maior contribuição do orçamento era proveniente das doações de pessoas jurídicas aos candidatos. No Brasil não existe uma cultura de doação por parte das pessoas físicas, diferentemente de outros países (BERMÚDEZ, 2016). As doações de pessoas jurídicas no país representavam cerca de $90 \%$ das arrecadações.

A lei também estipula uma limitação de gastos aos candidatos. Para quem disputa cargo de prefeito e vereador, o limite máximo das despesas é determinado com base nos maiores gastos declarados na circunscrição eleitoral durante as eleições anteriores. Essas resoluções legislativas, até a presente data de elaboração do artigo, se mostram incertas, mas dão margem para a possibilidade dos populares "caixa dois" das campanhas ser mais frequente (BRASIL, 2015).

A campanha foi reduzida para 45 dias, já o período de propaganda no rádio e na televisão passou 35 dias. A diminuição do tempo possui distintos impactos negativos. Inicialmente apontamos para a vantagem expressiva daqueles que já se encontram em cargo eletivo na disputa, pois sua lembrança está mais presente na mente dos eleitores. Com um tempo menor, consequentemente desencadeia menos debates políticos, propaganda, participação popular, engajamento e tempo hábil para que a percepção do candidato consolide com a intenção de votos em pesquisas eleitorais (BRASIL, 2015).

Um ponto positivo que vale ressaltar da mudança na legislação é que, antes da data oficial de registro, os candidatos poderão se anunciar como pré-candidatos. Com isso, ganham condições de convocar apoio político-partidário, expor ações desenvolvidas em prol da sociedade e realizar promessas eleitorais, sem que esses atos configurem propaganda antecipada. Mas o pedido de voto não pode ser realizado.

A presente pesquisa também abordará o tempo de exposição ${ }^{1}$ da propaganda eleitoral, que conta com dois blocos no rádio e na televisão com dez minutos cada, mais 70 minutos diários em inserções (de 30 ou 60 segundos), divididos em: prefeito com 60\% e vereadores

\footnotetext{
${ }^{1}$ Disponível em: <http://www.justicaeleitoral.jus.br/arquivos/tre-ba-cartilha-alteracoes-na-legislacao-eleitoral-
} lei-no-13-165-2015>. Acessado em 01 mar. 2017. 
com 40\%. Nas coligações partidárias, o tempo de propaganda será o coeficiente da totalização de representantes dos partidos que compõem a aliança.

\section{Metodologia}

No que diz respeito à natureza, classifica-se o trabalho como uma pesquisa básica, exploratória (GIL, 2002) e bibliográfica para coleta de dados. As informações são quantitativas do levantamento (OLIVEIRA, 1999), quanto a sua natureza, e foram tratadas de forma qualitativas (GERHARDT e SILVEIRA, 2009). Sendo assim, o foco não está direcionado à apresentação estatística dos dados da amostra, mas à análise e a interpretação dos resultados oriundos dos dados.

Para a compreensão do relacionamento digital que os candidatos aos cargos políticos buscaram estabelecer com os eleitores conectados as suas páginas na rede social Facebook, foram utilizados como base dois construtos metodológicos:

a) Caseiro e Barbosa (2011) - Sua análise abrangeu uma problemática que buscou compreender a forma com que a rede social digital foi utilizada por operadoras de telecomunicações portuguesa, no que diz respeito à interação, comunicação e promoção na rede. Também foram avaliados os níveis de interação e aceitação por parte dos usuários. Por meio da metodologia de análise dos dados com um viés qualitativo, centrada no fato de que não emprega um instrumento estatístico como base da metodologia de análise (RICHARDSON, 1999); porém é baseado em dados quantitativos provenientes do levantamento;

b) De Vries, Gensler e Leeflang (2012) - Sua pesquisa determinou possíveis direcionamentos para a popularidade de uma marca dentro do Facebook, por conta de características interativas nos posts. Os autores analisaram postagens de marca de 11 marcas internacionais distribuídas em diferentes categorias de produtos.

Os construtos metodológicos originais foram recortados e adaptados para atender as necessidades do fenômeno político social aqui investigado. Vale ressaltar, para fins de transparência e formalidades acadêmicas, que o novo construto desenvolvido neste estudo não é corroborado pelos autores. Os contextos científicos, políticos e sociais em que foram concebidos e aplicados torna o construto único e diferente das suas matrizes originais.

Para objeto aqui investigado foi selecionado a partir do período temporal de 26 de agosto de 2016, início da propaganda eleitoral gratuita no rádio e televisão regulamentados 
pelo TSE (Tribunal Superior Eleitoral), para que a coleta de dados pudesse ser realizada. Seguindo esta normativa, como justificativa, a coleta se encerrou em 29 de setembro de 2016. Logo após iniciou-se a análise, levando em consideração todas as atualizações e publicações contidas no período de temporal determinado. Desta forma foram separados e compilados diferentes tipos de conteúdo que estavam de forma dispersas nas páginas investigadas. Posteriormente, esquematizamos a divisão dos conteúdos por diferentes categorias/classificações que foram definidas e subdivididas para melhor alocar as informações coletadas.

O corpus principal da investigação abrange o primeiro turno da campanha eleitoral de 2016 para a prefeitura do município de Blumenau. O quadro geral da campanha era composto por cinco candidatos a prefeito. Mas para essa análise afunilaremos a abrangência para apenas os dois candidatos com menor tempo de exposição no rádio e televisão, estabelecido pelo TSE de acordo com a composição de cada coligação.

Embora as informações gerais tratadas neste artigo sejam de domínio público, os candidatos investigados foram identificados através de letras no decorrer da análise. Desta forma fica reiterada a imparcialidade político-partidária dos autores, evitando possíveis transtornos oriundos de polarizações políticas. E mesmo assim assegurando a informação de confidencialidade na coleta de dados. Neste sentido, os candidatos pesquisados serão denominados de: "Candidato A", com 35 segundos de exposição; "Candidato B", com o tempo de 33 segundos nos veículos de rádio e televisão. E, por fim, após o recorte metodológico realizado, os dados extraídos serão analisados e relacionados à luz de diferentes teorias abordadas pelos autores do marco teórico.

\section{Apresentação e discussão dos resultados}

Para realizar o estudo proposto foram analisados dois candidatos ao cargo de prefeito no município de Blumenau/SC, durante o primeiro turno da eleição de 2016. Os critérios de escolha dos prefeituráveis investigados levou em consideração os que tinham menor tempo de exposição durante o horário eleitoral gratuito no rádio e televisão. Os candidatos tinham o tempo de 35 (A) e 33 (B) segundos. Com o tempo reduzido para 35 dias de campanha e com a limitação nos veículos de comunicação, as redes sociais se apresentaram como soluções para apresentar os planos de governo e estreitar a distância com os eleitores. 
Na ocasião, o Facebook contabilizava 1,79 bilhão de usuários mensalmente, em que mais de 90\% o acessam através de aparelhos móveis (BLEIER, 2016). No Brasil, é a rede social de maior penetração, com 90,11 milhões (VALENTE, 2017) por mês, o que corresponde a $45 \%$ de toda a população, segundo o IBGE.

Essas estatísticas fazem com que a plataforma seja o principal palco digital para que os candidatos desenvolvam suas estratégias de comunicação a fim de se aproximar dos eleitores. Vale destacar a importância os termos "visíveis" nesta investigação. Devido às opções de privacidade que o Facebook disponibiliza, cada usuário tem autonomia para definir que os conteúdos publicados sejam visíveis somente para determinadas grupo de amigos ou pessoas ligadas a estas amizades. Neste sentido, alguns elementos podem não estar disponíveis para visualização pública, impossibilitando a análise de todos os comentários realizados neste estudo.

$\mathrm{Na}$ primeira etapa foram analisadas todas as postagens dos candidatos A e B dispostas em cada uma das suas respectivas fan pages, para, posteriormente executar a classificação teórico-metodológica de cada interatividade. O Gráfico 1 demonstra a quantidade de postagens realizadas durante o período de coleta de dados.

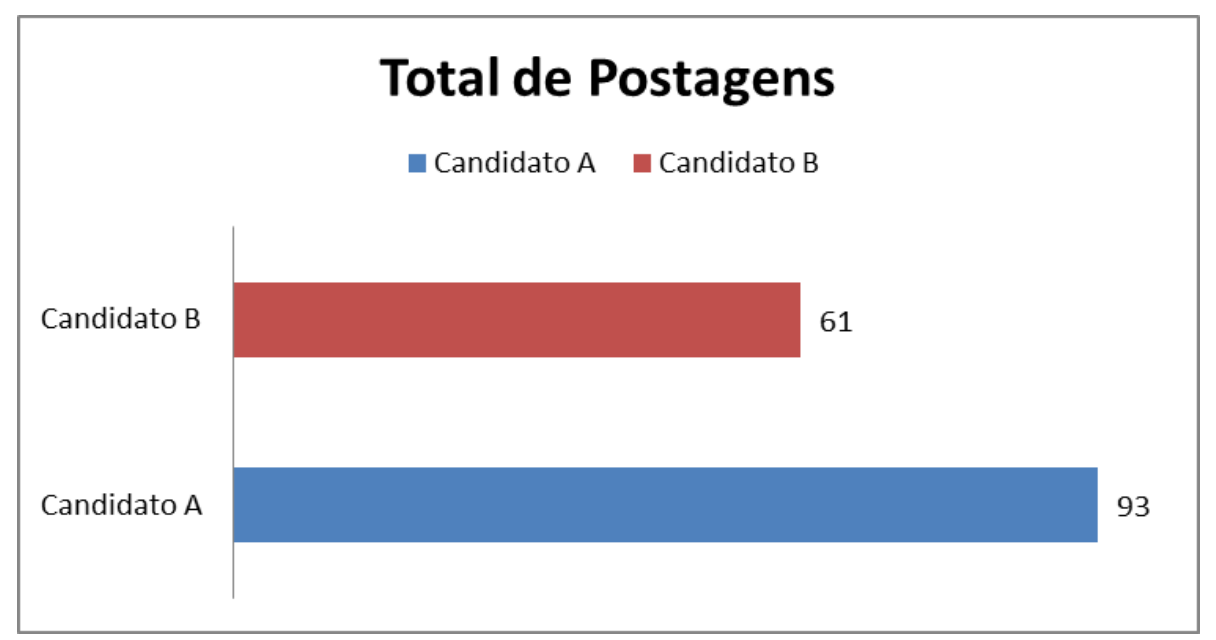

Gráfico 1 - Total de postagens nas fan page dos "Candidato A e B".

Fonte: Elaborado pelos autores.

Desdobrando a temática do Gráfico 1, identificamos o fluxo de conteúdo publicado por ambos os candidatos, para segmentar o teor das suas postagens. As classificações das categorias de publicações tiveram a flecha causal inicialmente de abranger os temas abordados por ambos os candidatos. No decorrer da aglutinação das informações, foi diagnosticado que os candidatos A e B compactuavam da mesma lógica de postagens no que 
se refere às suas estratégias comunicacionais. Sendo assim, foi possível desenvolver dimensões que comportassem as publicações das duas páginas investigadas, como visualizadas a seguir.

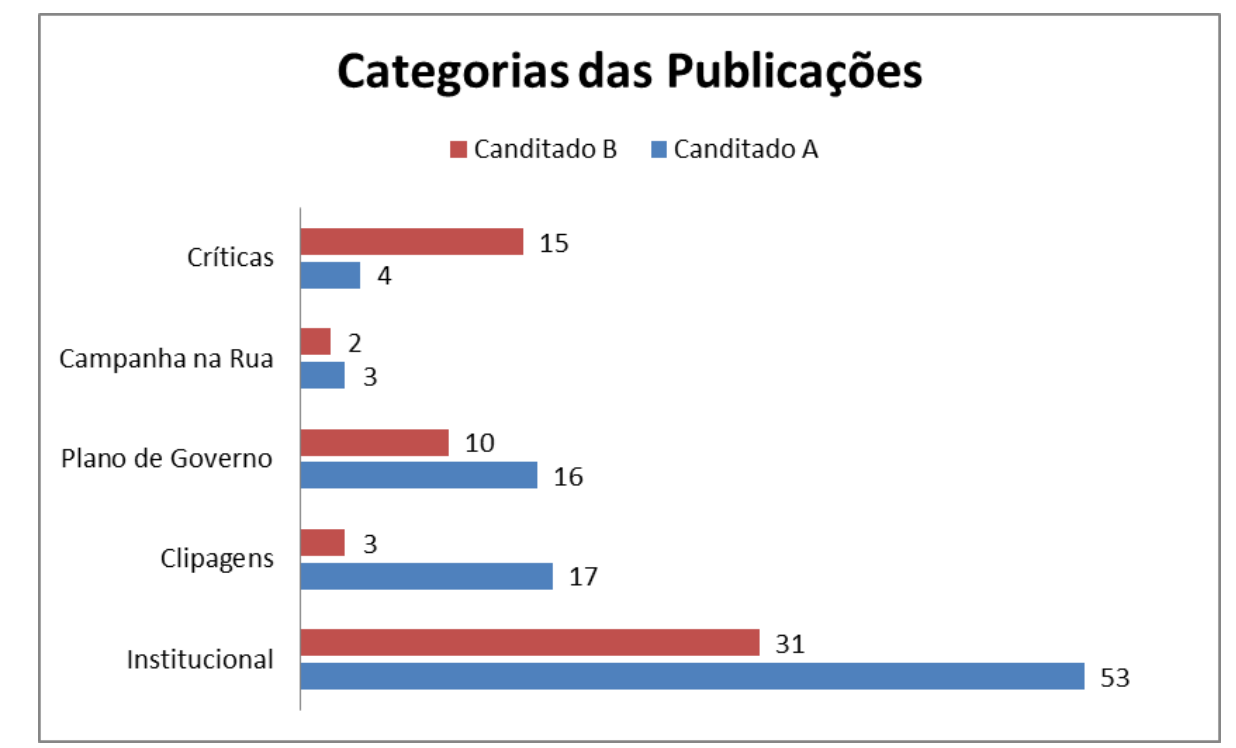

Gráfico 2 - Total das "Categorias de Publicações" nas fan page dos "Candidato A e B". Fonte: Elaborado pelos autores.

As categorias de publicações compreendem as temáticas: Críticas; Campanha na Rua; Plano de Governo; Clipagens e Institucional. Faz-se necessário identificar os principais pontos que cada tópico destacado, para analisar a abordagem desencadeada em cada uma das categorias.

Categoria "Críticas": Nesta categoria as publicações faziam críticas diretamente voltadas para os dois candidatos de maior tempo de exposição no programa eleitoral gratuito - um deles buscava a reeleição e o outro já tinha um cargo junto a Câmara Estadual do Estado. Neste sentido, eram os candidatos de maior respaldo político e que lideravam a intenção de votos dos eleitores de Blumenau. De acordo com dados estatísticos do Instituto Mapa, nos processos eleitorais passados voltaram a se repetir na pesquisa eleitoral, registrada no Tribunal Regional Eleitoral (TRE) sob o número SC-07802/2016 (SANTOS, 2016). Este item é importante porque, em toda a coleta de dados, este é o único item em que o candidato B foi superior ao candidato A no volume de publicações. Mesmo sem conhecer o teor das publicações, esse dado aponta como a linha editorial das publicações tinha um viés mais agressivo se comparado ao candidato A.

Categoria "Campanha na Rua”: nestas postagens foram reunidas as ações do candidato, do partido e de seus militantes nas ruas propriamente ditas. São situações em que o 
candidato realizava contato direto com a comunidade, seja em uma visita em casa de eleitores ou promovendo caminhadas e bandeiraços pelas ruas da cidade. Além da ação direta do prefeiturável, cabem nesta classificação manifestações de apoio dos eleitores, como imagens de carros com adesivos da campanha, eleitores colando adesivos no peito, crianças com bandeiras ou balões nas mãos e assim por diante. De uma forma geral, o enquadramento poderia envolver matérias de campanha que estivem em contato direto com os eleitores, e dessa forma, dar a sensação de volume, presença e engajamento por parte dos eleitores às intenções dos candidatos.

Categoria "Plano de Governo": essas publicações abordavam as principais ideias que cada candidato planejava para os próximos anos à frente da administração pública da cidade. O Plano de Governo é uma referência das ideias do candidato e de sua agremiação política. É a partir dele que, ao menos teoricamente, o eleitor deveria julgar o que é mais relevante. De uma forma ampla, o plano detalha os planejamentos que podem ser alterados visando o atendimento da população em todas as áreas, tais como: saúde, educação, mobilidade urbana, infraestrutura, segurança, economia e demais ramificações da administração de uma cidade. É importante destacar que, embora os candidatos fossem distintos, ambos discorriam suas propostas sobre os mesmos pontos, com pequenas diferenças de discursos e poucos pontos divergentes.

Categoria "Clipagens": Neste agrupamento, os candidatos publicavam as aparições em veículos de comunicação (rádio, jornal, revista e televisão) em que foram citados. Além disso, usavam publicações antigas da imprensa para dar respaldo aos seus próprios atos em prol da cidade, adicionando credibilidade as suas ideias e feitos. A clipagem de matérias jornalísticas também foi usada com a finalidade de evidenciar problemas no município ignorados pelos candidatos com maior tempo durante a propaganda eleitoral. As reportagens usadas nos posts concedem veracidade e autoridade na validação de uma informação. Essa lógica leva em consideração à ética e a apuração imparcial das informações que cabe às práticas da imprensa realizar em tudo que notícia.

Categoria "Institucional": E por fim, esta categoria não remetia diretamente ao ato de pedir voto para o candidato em si, mas pretendia conscientizar o eleitor sobre a importância do ato de votar. O conceito por trás dessas postagens é convencer o eleitor a participar do processo democrático e esclarecer o papel significativo que cada eleitor tem no pleito. Também se enquadraram nessa categoria postagens que falavam dos partidos de que os 
candidatos A e B faziam, e dos seus elementos ideológicos que os diferenciavam dos demais concorrentes.

A partir de um recorte teórico-metodológico de Caseiro e Barbosa (2011) e de De Vries, Gensler e Leeflang (2012), foram definidas três tipologias de engajamento (Gráfico 3) para cada uma das postagens dos "Candidato A e B". São elas: Comentários; Compartilhamento e Reactions.

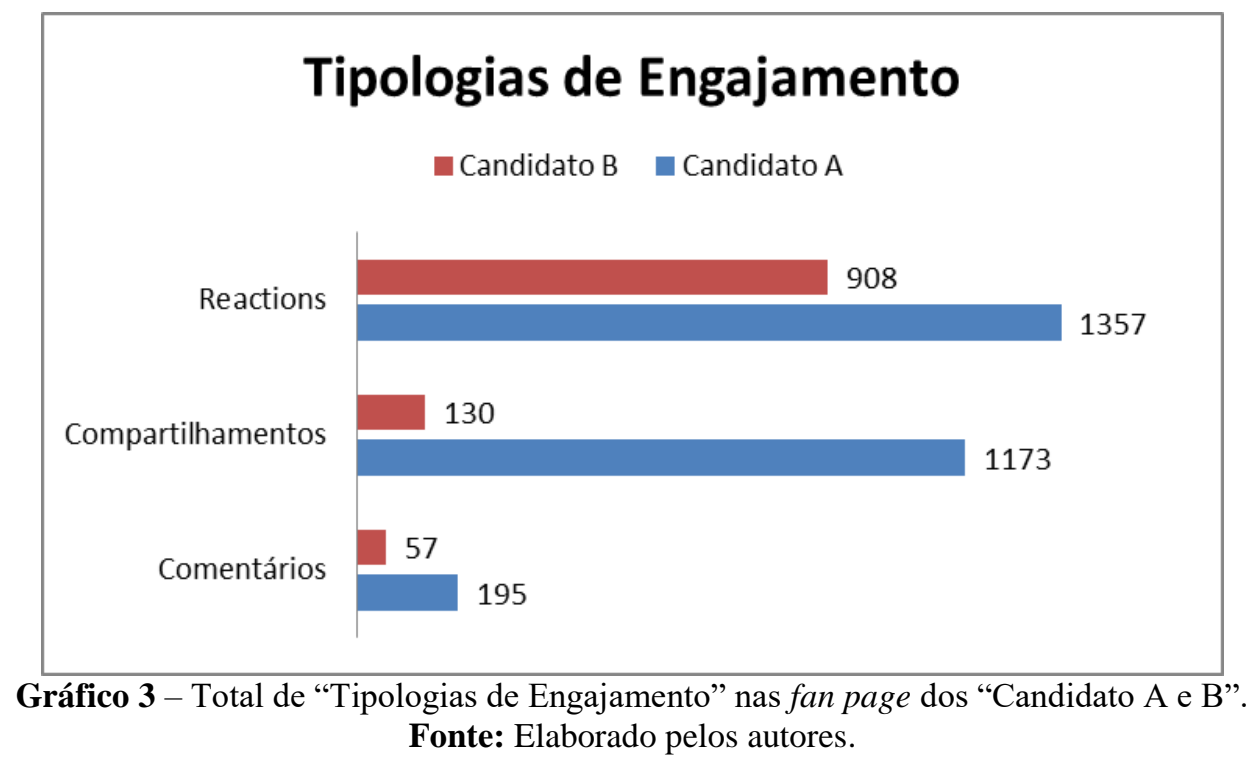

As tipologias, por sua vez, foram subdivididas em novas categorias para que pudessem ser agrupadas e relacionadas com cada uma das publicações analisadas das respectivas fan pages. São elas:

a) Categorias dos Comentários (Gráfico 4): Todos os comentários realizados em cada postagem foram agrupados e relacionados com as publicações analisadas: Elogios/Interações Espontâneas; Marcações ou Interações Entre Usuários; Dúvidas; Críticas/Reclamações ao Candidato; Críticas a Outros Candidatos; Spam; Respostas do Candidato. 


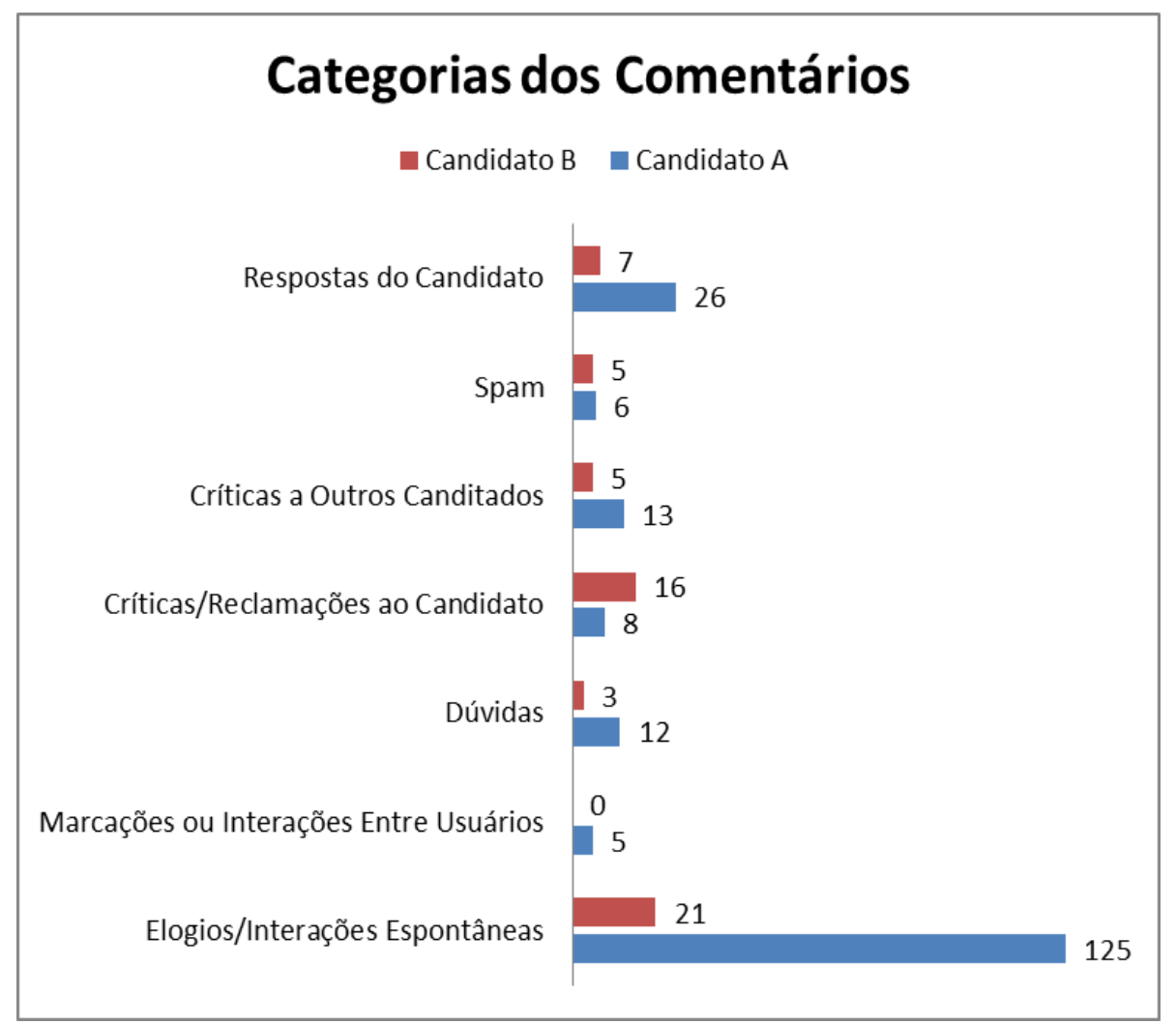

Gráfico 4 - Total das "Categorias dos Comentários" nas fan page dos "Candidato A e B". Fonte: Elaborado pelos autores.

Faz-se necessário detalhar cada agrupamento de comentários realizados nas publicações das fan pages investigadas com a finalidade de discernir as características que as diferenciam:

Elogios/Interações Espontâneas: nesta categoria foram agrupados todos os comentários que interagiram diretamente com o conteúdo proposto pelo candidato. Estas interações podem ser uma resposta direta, provocada intencionalmente pela página em sua publicação, ou um comentário espontâneo demonstrando simpatia ao político, partido, ideia, posicionamento ou plano de governo.

Marcações ou interações entre usuários: foram agrupados todos os comentários que indicam a interação entre os usuários, através da marcação do nome de indivíduos nas publicações. Também foram consideradas todas as outras interações realizadas entre usuários no campo de comentários da página. Alguns usuários contribuíam com questionamentos realizados entre si.

Dúvidas: foram congregadas todas as indagações feitas pelos usuários para a página. Vale ressaltar que, uma das principais técnicas adotadas pela fan page para incentivar a interação do público, se faz por meio de questionamentos aos mesmos. Contudo, em nenhum 
momento durante o período analisado, houve qualquer contrapartida dos administradores da página em responder aos questionamentos feitos pelos internautas.

Críticas/Reclamações ao Candidato: no decorrer da análise dos comentários, percebeu-se a maneira como muitos usuários acompanharam e interagiram com as páginas tanto para expressar seu posicionamento político, como também o utilizam em forma de palanque, para expor suas opiniões a respeito do candidato, do partido ou das ideias apresentadas. Do mesmo modo, por meios destas Críticas/Reclamações ao Candidato os usuários esperam por explicações ou soluções dos problemas abordados.

Críticas a Outros Candidatos: diferentemente das reclamações, os usuários interagiam com os candidatos por meio da exposição de ideias e complementos, vistos por estes como melhorias para as ideias apresentado. Mas para a concretização de uma linha de raciocínio, criticavam os candidatos que estavam no páreo da disputa eleitoral que se opunham as vertentes políticas defendidas pelos candidatos das respectivas páginas investigadas.

Respostas do candidato: foram reunidos todos os comentários nos quais os “Candidatos A e B" interagiram com a finalidade de responder os comentários realizados nas fan pages. Vale ressaltar que não foi analisado o conteúdo dessas respostas. Observações quanto a sua forma ou estratégia foram desconsideradas, apenas o ato em si de responder um determinado questionamento foi considerado relevante para a finalidade desse estudo.

Spam: Por fim, foi agrupado os comentários que faziam referências a outras páginas ou conteúdo, sem qualquer coerência com a temática política apresentada pela página dos candidatos A e B. Compreende-se este tipo de ação como uma maneira de transferir a atenção para outro foco, desviando assim a finalidade da postagem realizada, ou mesmo com a intenção de diminuir a credibilidade de algo apresentado.

b) Categorias das Reactions (Gráfico 5): O Facebook, em sua atualização de 15 de outubro de $2015^{2}$ adicionou cinco emojis animados denominados de: "Amei", "Haha" (alegre), "Uau" (surpresa), "Triste" e "Grr" (bravo) juntamente ao botão de "Curtir". Sua utilização tem a intenção de interpretar mais nuances das reações humanas dentro do contexto digital. Além de substituiu o botão de "Não Curtir", que era reivindicado pelos usuários da rede social.

\footnotetext{
${ }^{2}$ Disponível em: < https://www.facebook.com/zuck/videos/10102412343501081/>. Acessado em 07 nov. 2016.
} 


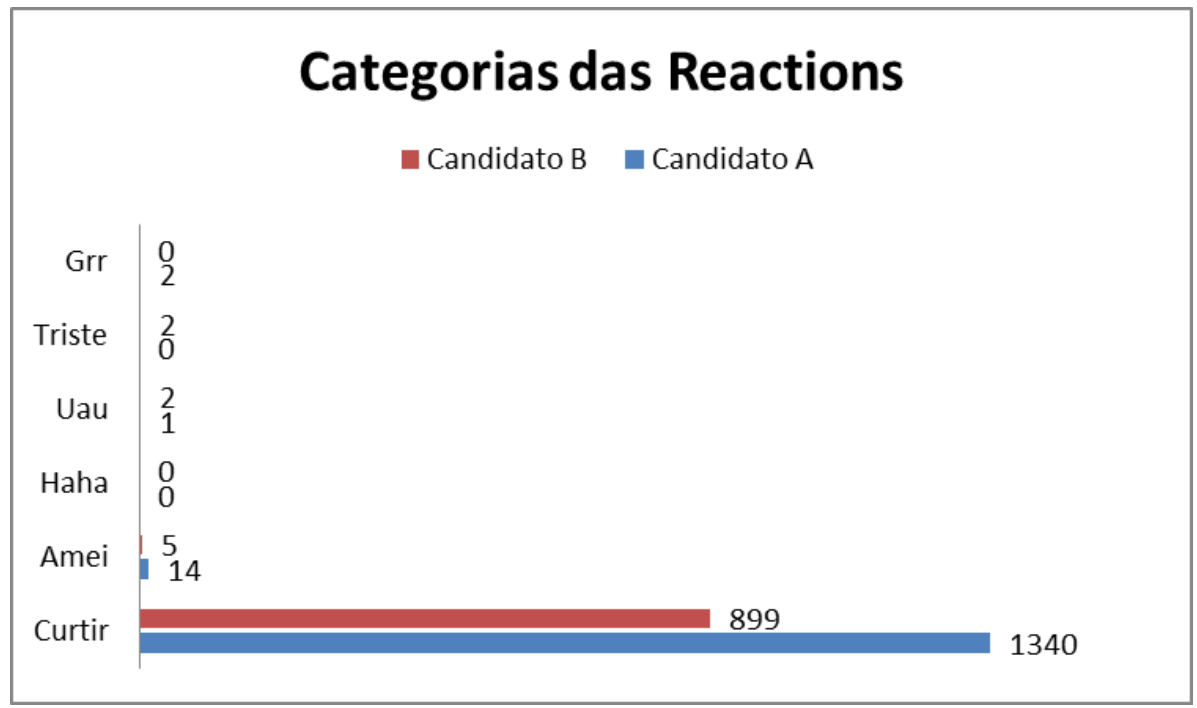

Gráfico 5 - Total das "Categorias das Reactions" nas fan page dos "Candidato A e B". Fonte: Elaborado pelos autores.

A partir da análise individual das "Tipologias de Engajamento" presentes nas publicações, faremos uma ponderação de espectro amplo sob os dados resultantes destas análises, relacionando-os com as teorias da comunicação abordadas no decorrer da fundamentação teórica do presente artigo. O desígnio de uma análise é congregar as observações de forma coerente e estruturada, com o propósito de elucidar a problemática da pesquisa. Essa interpretação propicia um espectro amplo dos dados agrupados e faz uma correlação entre eles e o conhecimento existente (DENCKER, 2000).

É importante compreender que o "Candidato A" realizou 93 postagens e o "Candidato B”, apenas 61 (Gráfico 1), sendo assim, já identificamos de primeiro momento uma diferença no volume de conteúdo desenvolvido pelos objetos analisados. O que resultará em uma diferença natural no decorrer da análise, visto o número maior de publicações. "Esse momento crucial de visibilidade e imediatismo, são objetivações, classificações a maioria das vezes construídas a posteriori para dar nexo e tentar explicar o mundo que passou ou o mundo em que estamos vivemos" (BARBOSA, 2012, p. 147). Neste caso, a quantidade de conteúdo tem ligação direta com os resultados comunicacionais que a pesquisa visa identificar.

O Gráfico 3 aborda as "Tipologias de Engajamento", que são constituídas por: Comentários; Compartilhamento e Reactions. Começamos a visualizar como a diferença no volume de publicações começa a influenciar no resultado. Com relação aos compartilhamentos, o candidato A atingiu 1.173, contra apenas 130 do candidato B. Vale ressaltar que a dinâmica digital de compartilhamento do Facebook faz com que uma postagem consiga expandir seu raio de leitura dentro da plataforma, que "[...] é resultado de um jogo 
acumulativo dos processos [...]" (BARBOSA, 2012, p. 149). Quanto mais usuários compartilharem uma publicação, maior será o número de pessoas impactadas pela mensagem.

Como o candidato A teve um número superior de compartilhamento em suas postagens, o número de Reactions (Gráfico 5) também atingiu os índices elevados de 1.357. Enquanto isso, o candidato B desencadeou apenas 130 reações interacionais.

Detalhando os Reactions, que se dividem em "Curti", "Amei", "Haha" (alegre), "Uau" (surpresa), "Triste" e "Grr" (bravo); os dados extraídos das postagens indicam que o clássico botão "Curtir" foi à reação mais utilizada em todas as postagens de ambos os candidatos. O candidato A atingiu 1.340 likes, já o candidato B obteve 899 "curtidas". Aqui se faz necessário algumas ponderações sobre a dinâmica interacional originadas dos Reactions. Essas novas linguagens de interações foram liberadas para os usuários do Brasil apenas em 24 de fevereiro de $2016^{3}$, embora tenham sido criadas em outubro de 2015 para usuários de outros países. "Não devemos assumir apenas que o presente é o lugar da comunicação. Nada começa hoje" (BARBOSA, 2012, p. 149).

A ativação dos Reactions não se mostra totalmente intuitiva para parte dos usuários, já que para seu acionamento o indivíduo precisa segurar o botão de "Curtir" por alguns segundos para que as demais nuances de expressões surjam na tela. Levando em consideração que a maior parte dos acessos a Internet no Brasil, em especial no Facebook, são realizados pelo mobile, segundo o relatório TIC Domicílios $2015^{4}$, devemos ponderar que nem todos os usuários dominam seu acionamento. Em relação a essas novas linguagens, percebe-se alguns conflitos sobre os termos emoji, emoticons e smiles, ícones utilizados na comunicação online (POMPEU e SATO, 2015).

Uma prova empírica dessa falta de expertise do usuário, envolvendo o acionamento dos botões: "Amei", "Haha" (alegre), "Uau" (surpresa), "Triste" e "Grr" (bravo); pode ser visualizado nos baixos números de interações nas publicações de ambos os candidatos analisados nessa pesquisa. As causas que esta pesquisa aponta podem ser: desconhecimento da própria existência da ferramenta; saber da sua existência e desconhecer o acionamento; saber da existência, mas desconhecer em que situações são empregadas; ter a ciência da ferramenta, mas não usar com receio de ser mal interpretado. Neste sentido, cabe compreender que os “[...] ambientes tecnológicos não são recipientes puramente passivos de

3 "Facebook libera cinco novos botões alternativos ao 'curtir'، . Disponível em: < http://g1.globo.com/tecnologia/noticia/2016/02/facebook-libera-cinco-novos-botoes-alternativos-ao-curtir.html>. Acessado em 08 nov. 2016.

${ }^{4}$ Disponível em: < http://cetic.br/media/analises/tic_domicilios_2015_coletiva_de_imprensa.pdf >. Acessado em 08 nov. 2016 
pessoas, mas ativos processos que remodelam pessoas e igualmente outras tecnologias" (MCLUHAN, 1965, p. 15).

Mesmo o candidato A, apresentando um desempenho comunicacional superior ao seu opositor de acordo com os dados levantados e à luz dos autores desenvolvidos neste estudo, não obteve êxito em transformar as interações em votos. "Cada época constrói, a partir de um conjunto de práticas, um rosto histórico singular que acreditamos reconhecer e que nomeamos como [...] práticas e processos comunicacionais”. (BARBOSA, 2012, p. 146-147). Ao fim do primeiro turno da votação, os números apontados na apuração das urnas de acordo com o $\mathrm{TRE}^{5}$, indicaram o seguinte resultado: o candidato A obteve 10.855 votos, o que corresponde a 6\% do total de eleitores do município. Já o candidato B alcançou 16.652 votos, correspondentes a 9,21\% do eleitorado. Vale ressaltar que o número total de votos apurados no processo eleitoral foi de 209.344.

Esta divergência entre a análise na principal plataforma digital dos candidatos e os números alcançados nas urnas mostra que os eleitores não estabeleceram uma digitalização da sua dinâmica interpessoal para escolher seu representante no poder municipal. Sendo assim, podemos concluir que a identidade do usuário com a dinâmica comunicacional não é algo acabado, mas é construído socialmente e depende da interação social, política e econômica que pode existir (BAUMAN, 2009).

Blumenau desempenha papel estratégico para diversos partidos políticos na configuração de um projeto eleitoral em 2018. “[...] O presente transforma-se no lugar natural da reflexão dos processos comunicacionais. É como se apenas o presente comportasse o ato comunicacional" (BARBOSA, 2012, p. 145). Juntamente com Florianópolis e Joinville, o município forma o triângulo dos principais colégios eleitorais do Estado, locais cujo processo sucessório contempla a realização da escolha em dois turnos. A vitória ou derrota nestes territórios estratégicos esboçam o procedimento de transição que o Estado tenderá a transpor quando os eleitores retornarem as urnas. Por fim, entende-se que "[...] grandes mudanças nos modos ordinários de falar e agir do homem estão ligados à adoção de novos instrumentos" (MCLUHAN, 1965, p. 24).

\footnotetext{
${ }^{5}$ Disponível em: < http://www.tresc.jus.br/site/fileadmin/arquivos/eleicoes/eleicoes2016/resultado_turno_1/relatorios_totalizacao_municipio/TOT 2016_BLUMENAU.pdf>. Acessado em 08 nov. 2016.
} 


\section{CONSIDERAÇÕES}

As mídias sociais permitem que os eleitores obtenham proximidade dos candidatos no novo modelo de eleição reconfigurada pela TSE. Dentre os caminhos percorridos nesse artigo para alcançar seus objetivos, buscou-se analisar o fluxo de conteúdo e as interações comunicacionais dos usuários e candidatos desencadeadas na rede social digital Facebook, durante as eleições de 2016 na cidade de Blumenau/SC e as possíveis mudanças das práticas e processos comunicacionais.

Neste sentido, identificou-se que a campanha eleitoral de 2016 no Brasil limitou a arrecadação de fundos e criminalizou o clássico modelo de marketing e as propagandas no horário eleitoral, impelindo um papel estratégico no âmbito comunicacional para a apresentação dos candidatos. A redução no tempo de campanha em rádio e televisão, por conta das coligações partidárias, influenciou as condições de trabalho dos prefeituráveis analisados e dificultou a comparação entre as plataformas de governo. Isso porque as mudanças exigiram que o eleitor tivesse que buscar, nas plataformas digitais, as informações para influenciar sua tomada de decisão junto às urnas.

Levando em consideração a própria lógica da rede social investigada, as bolhas invisíveis que regem cada perfil de usuário, as postagens dos candidatos tiveram dificuldade de reverberar pelas timelines apenas de forma orgânica. Sendo assim a própria interação fica comprometida, uma vez que atenção dos eleitores tende a se dispersar pela grande quantidade de conteúdo que competem entre si. Concluímos que é preciso repensar a forma de abordar a política e do uso do marketing digital, desde a imprensa até os candidatos. A temática deve atrair o cidadão para algo que é fundamental a sua vida em sociedade, mesmo que muitos não se deem conta.

\section{REFERÊNCIAS}

BARBOSA, M. "O presente e o passado como processo comunicacional", in Revista Matrizes, 2012, v. $5, n^{\circ} 2$, p. $145-155$

BERMÚDEZ, Á. Quanto custam as eleições nos EUA e como elas se comparam com outros países. BBC Brasil. 2016. Disponível em:〈http://www.bbc.com/portuguese/internacional-37864609>. Acessado em 01 mar. 2017.

BLEIER, K. Lucro líquido do Facebook quase triplica, para US\$ 2,37 bilhões. O Globo. 2016. Disponível em: <http://oglobo.globo.com/economia/lucro-liquido-do-facebook-quase-triplica-para-us237-bilhoes-20402931>. Acessado em 01 mar. 2017. 
BRASIL. Lei n. 13.165, de 29 de setembro de 2015. Código Eleitoral, para reduzir os custos das campanhas eleitorais, simplificar a administração dos Partidos Políticos e incentivar a participação feminina. Ano CLII, n.186-A, Brasília - DF. Disponível em: <

http://www.planalto.gov.br/ccivil_03/_ato2015-2018/2015/lei/113165.htm>. Acessado em 01 mar. 2017

BAUMAN, Z. Identidade. Rio de Janeiro: Jorge Zahar Editor, 2005.

BAUMAN, Z. A sociedade individualizada: vidas contadas e histórias vividas. Rio de Janeiro: Zahar, 2009.

CASEIRO, B.; BARBOSA, R. Empresas no Facebook: o caso da TMN e da Optimus. Internet Latent Corpus Journal, v.2, n.1, p. 6-15, 2011. Disponível em: < http://revistas.ua.pt/index.php/ilcj/article/view/1276/1173>. Acessado em: 01 mar. 2017.

CASTELLS, M. A sociedade em rede. v 1. 13. reimpr. Trad. Roneide Venancio Majer. São Paulo: Paz e Terra, 2010.

CHIAVENATO, I. Introdução a Teoria Geral da Administração, $8^{a}$ ed. Rio de Janeiro: Elsevier, 2011.

DENCKER, A. F. M. Métodos e técnicas de pesquisa em turismo. 4. ed. São Paulo: Futura, 2000.

DE VRIES, L.; GENSLER, S.; LEEFLANG, P. SH. Popularity of brand posts on brand fan pages: An investigation of the effects of social media marketing. Journal of Interactive Marketing, v. 26, n. 2, p. 83-91, 2012.

FARRELL, D. M.; KOLODNY, R.; MEDVIC, S. Parties and Campaign Professionals in a Digital Age Political Consultants in the United States and Their Counterparts Overseas. The Harvard International Journal of Press/Politics, v. 6, n. 4, p. 11-30, 2001.

FARRELL, D. M.; WEBB, P. Political parties as campaign organizations. Parties without partisans: Political change in advanced industrial democracies, p. 102-28, 2000.

FRASER, J.; FRASER, N.; MCDONALD, F. The strategic challenge of electronic commerce. 2000. Disponível em: <http://www.emeraldinsight.com/journals.htm?articleid=858192> Acesso em: 22 nov. 2016

GABRIEL, M. Marketing na era Digital. São Paulo: Novatec, 2010.

GERHARDT, T. E.; SILVEIRA, D.T. Métodos de pesquisa. UFRGS Editora. Rio Grande do Sul, 2009.

GIL, A. C. Como elaborar projetos de pesquisa. 4a ed. São Paulo: Atlas, 2002.

GOMES, W. et al. "Politics 2.0": Barack Obama's on-line 2008 campaign. Revista de Sociologia e Política, v. 17, n. 34, p. 29-43, 2009.

HOWARD, P. N. Deep democracy, thin citizenship: The impact of digital media in political campaign strategy. The annals of the American Academy of Political and Social Science, v. 597, n. 1, p. 153170, 2005.

KOTLER, P., KARTAJAYA, H., SETIWAN, I. Marketing 4.0: do tradicional ao digital. Rio de Janeiro: Sextante, 2017. 
LEPPÄNIEMI, Matti et al. Targeting young voters in a political campaign: Empirical insights into an interactive digital marketing campaign in the 2007 Finnish general election. Journal of Nonprofit \& Public Sector Marketing, v. 22, n. 1, p. 14-37, 2010.

MCLUHAN, M. A galáxia de Gutenberg. 1965 (p.15-27)

MORAES, F. Planejamento estratégico digital: a importância de planejar a comunicação da marca no ambiente digital. Rio de Janeiro: Brasport, 2006.

OLIVEIRA, S. L. Tratado de metodologia científica: projetos de pesquisas, TGI, TCC, monografias, dissertações e teses. 2a ed. São Paulo: Pioneira, 1999.

OLIVEIRA, W. P. A. A influência da Comunicação nas decisões das empresas em transição para internet. Campina Grande, 2000.

PEREIRA, V. Índice de abstenção de SC é o terceiro menor. Click RBS. 2016. Disponível em: < http://www.clicrbs.com.br/jsc/sc/impressa/4,3782,7660324,29830>. Acessado em 01 mar. 2017.

POMPEU, B.; SATO, S. K. Iconoliteracia publicitária: a linguagem complexa dos emojis na propaganda brasileira. In: Congresso Brasileiro Ciências da Comunicação, INTERCOM, XXXVIII, 2015. Disponível em: <http://portalintercom.org.br/anais/nacional2015/resumos/R10-32081.pdf>. Acesso em 07 nov. 2016.

RICHARDSON, R. J. Pesquisa social - métodos e técnicas. 3. ed. São Paulo: Atlas, 1999.

SANTOS, J. Primeira pesquisa eleitoral de 2016 traz Jean Kuhlmann na frente em Blumenau. Notícias do Vale. 2016. Disponível em: <http://www.noticiasvaledoitajai.com.br/noticia/primeira-pesquisaeleitoral-de-2016-traz-jean-kuhlmann-na-frente-em-blumenau/>. Acessado em 01 mar. 2017.

SANZ, M. J. P. Weblogs as a Subgenre of Political Communication/Marketing. Revista de Lingüística y Lenguas Aplicadas, v. 2, n. 1, p. 57-68, 2010.

TELLES, A. A revolução das mídias sociais: Cases conceitos, dicas e ferramentas. São Paulo: M. Books do Brasil, 2010.

VALENTE, J. Internautas brasileiros acham que a internet se resume ao Facebook. Carta Capital, 2017. Disponível em: https://www.cartacapital.com.br/blogs/intervozes/internautas-brasileiros-achamque-a-internet-se-resume-ao-facebook. Acessado em 01 mar. 2017.

Original recebido em: 02 de março de 2017

Aceito para publicação em: 17 de abril de 2018

Moisés Cardoso

Doutorando no PPGcom - Programa de Pós-Graduação em Comunicação e Linguagens (UTP Universidade Tuiuti Do Paraná). Mestre em Desenvolvimento Regional (FURB), Especialista em Novas Mídias, Rádio e TV (FURB). Graduação em Publicidade e Propaganda (FURB) e Jornalista (IBES/Sociesc). Docente nos cursos de Publicidade e Propaganda da FURB e Uniasselvi/FAMEG.

É integrante dos Grupos de Pesquisa: JOR XXI (PPGCom/UTP) e Estudos Midiáticos Regionais (PPGDR/FURB). 
Tarcis Prado Junior

Doutorando no PPGcom - Programa de Pós-Graduação em Comunicação e Linguagens (UTP Universidade Tuiuti Do Paraná). Mestre (UTP) e Relações Públicas (UMESP). Docente nos cursos de Comunicação e Marketing (UTP). É integrante do Grupo de Pesquisa: JOR XXI (PPGCom/UTP).

Franco Iacomini Junior Doutorando no PPGcom - Programa de Pós-Graduação em Comunicação e Linguagens (UTP Universidade Tuiuti Do Paraná). Jornalista e docente na Faculdade Fidelis. É integrante do Grupo de Pesquisa: JOR XXI (PPGCom/UTP)

Thaíse Schmitz Pós-graduanda em Marketing e Comunicação Digital (Dom Bosco). Bacharel em Publicidade e Propaganda (IBES/Sociesc).

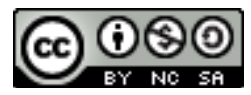

Esta obra está licenciado com uma Licença

Creative Commons Atribuição-NãoComercial-CompartilhaIgual 4.0 Internacional 